Review Article

\title{
Multiple Roles of 25-Hydroxycholesterol in Lipid Metabolism, Antivirus Process, Inflammatory Response, and Cell Survival
}

\author{
Qin Cao, ${ }^{1}$ Zhongzhong Liu, ${ }^{1}$ Yan Xiong, ${ }^{1}$ Zibiao Zhong, ${ }^{1}$ and Qifa Ye $\mathbb{D}^{1,2}$ \\ ${ }^{1}$ Zhongnan Hospital of Wuhan University, Institute of Hepatobiliary Diseases of Wuhan University, Transplant Center of \\ Wuhan University, Hubei Key Laboratory of Medical Technology on Transplantation, Engineering Research Center of Natural \\ Polymer-based Medical Materials in Hubei Province, Wuhan, China 430071 \\ ${ }^{2}$ The Third Xiangya Hospital of Central South University, Research Center of National Health Ministry on Transplantation Medicine \\ Engineering and Technology, Changsha, China 410013 \\ Correspondence should be addressed to Qifa Ye; yqf_china@163.com
}

Received 30 August 2020; Revised 25 October 2020; Accepted 26 October 2020; Published 20 November 2020

Academic Editor: Ilaria Peluso

Copyright ( 2020 Qin Cao et al. This is an open access article distributed under the Creative Commons Attribution License, which permits unrestricted use, distribution, and reproduction in any medium, provided the original work is properly cited.

As an essential lipid, cholesterol is of great value in keeping cell homeostasis, being the precursor of bile acid and steroid hormones, and stabilizing membrane lipid rafts. As a kind of cholesterol metabolite produced by enzymatic or radical process, oxysterols have drawn much attention in the last decades. Among which, the role of 25-hydroxycholesterol (25-HC) in cholesterol and bile acid metabolism, antivirus process, and inflammatory response has been largely disclosed. This review is aimed at revealing these functions and underlying mechanisms of 25-HC.

\section{Introduction}

Cholesterol is a member of the sterol family that plays essential roles in a variety of biological processes [1]. Under physiological state, cholesterol is mainly metabolized into bile acids and steroid hormones such as estrogens and androgens. In addition, cholesterol is also the crucial component of membrane lipid rafts [2]. In the past years, the function of this basic and pleiotropic molecule has been deeply studied. It is then realized that the derivatives of this precursor are implicated in a broad of physiological processes, such as cholesterol metabolism, antivirus process, and inflammatory and immune response, and are involved in a series of diseases development, such as atherosclerosis, neurodegeneration disease, inflammatory bowel disease, and nonalcoholic liver disease [3-7]. Among these cholesterol metabolites, oxysterols are 27-carbon molecules that are formed via enzymatic or radical process adding an epoxide or ketone or an additional hydroxyl group in the sterol nucleus and/or a hydroxyl group in the side chain [8]. These compounds are much more chemically reactive than cholesterol and are involved in a wider range of physiological processes.
In the past decades, side-chain oxysterols including 24S-, 25-, and 27-HC have drawn much attention [9-12]. Both 24S-HC and 27-HC are responsible for excessive intracellular cholesterol efflux in extrahepatic tissues like brain and macrophages. When compared with cholesterol, 24S-HC and 27-HC have greater polarity, thus can be transported to liver for further metabolism [9]. 24S-HC and 27-HC are considered to be the major players in mediating cholesterol efflux from extrahepatic organs to liver [9]. Specifically, 24S-HC is merely produced in the brain, owing to the exclusively expression of cholesterol 24-hydroxylase (CYP46A1) [11].

When compared to $24 \mathrm{~S}-\mathrm{HC}$ and $27-\mathrm{HC}, 25-\mathrm{HC}$ is a minor side-chain oxysterol formed by cholesterol 25hydroxylase $(\mathrm{CH} 25 \mathrm{H})$ [8]. As like other oxysterols, it was firstly thought that $25-\mathrm{HC}$ had a potent ability to mediate cholesterol homeostasis. However, this hypothesis came into question when the cholesterol homeostasis was not affected on the condition of $\mathrm{CH} 25 \mathrm{H}$ deficiency [13-15]. With the deep and broad investigations of this molecule, the veil of the involvement of $25-\mathrm{HC}$ in antivirus process and inflammatory and immune response has been disclosed [12]. Over the past decades, the roles of 25-HC in cholesterol and bile 

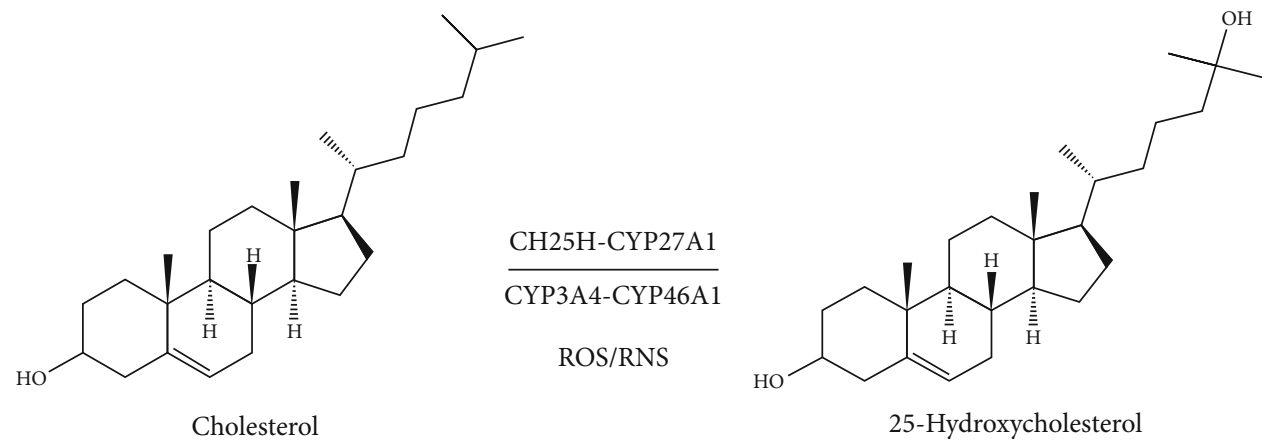

FIGURE 1: The production of 25-HC. Cholesterol can be catalyzed by enzymes CH25H, CYP3A4, CYP27A1, and CYP46A1 and reactive oxygen and nitrogen species (ROS/RNS) to 25-hydroxycholesterol.

acid metabolism, antivirus process, inflammatory and immune response, and survival signaling pathway have been widely investigated, and this review will depict the functions of $25-\mathrm{HC}$ in these processes as comprehensive as possible.

\section{25-HC Production}

25-HC is synthesized from cholesterol by the addition of a hydroxyl group at position 25-carbon. This reaction is catalyzed by $\mathrm{CH} 25 \mathrm{H}$, which is a member of a small family of enzymes that use oxygen and a di-iron cofactor to catalyze hydroxylation reaction [16]. $\mathrm{CH} 25 \mathrm{H}$ is located in endoplasmic reticulum and is ubiquitously expressed in tissues, especially in macrophages [17]. There is recent study indicating that $\mathrm{CH} 25 \mathrm{H}$ is highly expressed in mouse liver and peritoneal macrophages [18], although it was once considered that this protein was poorly expressed in healthy liver. In addition, a few of cytochromes (CYP3A4, CYP27A1, and CYP46A1) and even reactive oxygen and nitrogen species (ROS/RNS) can catalyze cholesterol to form this oxysterol $[15,19,20]$ (Figure 1). However, the effect of these enzymes on 25-HC production in vivo is poorly investigated.

\section{The Regulation of $\mathbf{C H} 25 \mathrm{H}$}

Intracellular $25-\mathrm{HC}$ content is mainly determined by $\mathrm{CH} 25 \mathrm{H}$ activity; thus, regulation of $\mathrm{CH} 25 \mathrm{H}$ is of great importance in $25-\mathrm{HC}$ production. $\mathrm{CH} 25 \mathrm{H}$ is a highly dynamically regulated enzyme and especially so in inflammatory conditions. Firstly, it was unexpectedly found that $\mathrm{CH} 25 \mathrm{H}$ was strongly upregulated in lipopolysaccharide (LPS; endotoxin) stimulated macrophages in vitro, and this increased $\mathrm{CH} 25 \mathrm{H}$ expression was independent of myeloid differentiation protein 88 (Myd88) signaling but dependent on toll-like receptor 4 (TLR4) signaling [21]. On the basis of this study, dendritic cells and macrophages were verified to be significant source of $\mathrm{CH} 25 \mathrm{H}$, and the TLR-mediated expression of $\mathrm{CH} 25 \mathrm{H}$ was dependent on TIR-domain-containing adapter-inducing interferon- $\beta$ (TRIF), production of type I interferons (IFNs), and signaling through the interferon production regulator (IFNR)/Janus kinase(JAK)/signal transducer and activator of transcription 1 (STAT1) pathway [17]. Subsequent study further validated the $C h 25 h$ as an INF-stimulated gene (ISG) via STAT1 pathway and $25-\mathrm{HC}$ as the only macro- phage synthesized and secreted oxysterol [22]. In addition, a cholesterol oxidation and efflux-related gene, krüppel-like factor 4 (KLF4) was recognized to be able to transactivate Ch25h in vascular endothelial cells and macrophages [23]. Recently, a study that is aimed at investigating the mechanisms regulating $\mathrm{CH} 25 \mathrm{H}$ expression found that $25-\mathrm{HC}$ itself was able to activate $\mathrm{CH} 25 \mathrm{H}$ expression, thus forming a positive feedback loop, and this effect was dependent on liver X receptors (LXRs), which were receptors of 25-HC [18]. Furthermore, inflammatory cytokine interleukin-1 $\beta$ (IL-1 $\beta$ ), tumor necrosis factor- $\alpha$ (TNF $\alpha$ ), and IL- 6 can also promote $\mathrm{CH} 25 \mathrm{H}$ expression through the STAT1 transcription factor in virus-infected human macrophages [24]. On the contrary, activating transcription factor 3 (ATF3) was reported to be a negative regulator of $C h 25 h$ gene by directly binding to the promoter of $\mathrm{Ch} 25 \mathrm{~h}$ and epigenetically repressing Ch25h expression [25] (Figure 2).

\section{The Receptors and Binding Proteins of 25-HC}

The past years' investigations have shown that $25-\mathrm{HC}$ is far more than just a kind of cholesterol metabolite. This molecule is an active mediator in a variety of physiological process. As an endogenous ligand, 25- $\mathrm{HC}$ binds to a strand of receptors $[8,26]$, including nuclear receptors LXRs $[27,28]$, retinoic acid receptor- (RAR-) related orphan receptors (ROR) $[29,30]$ and the estrogen receptor $\alpha(\operatorname{ER} \alpha)[31]$, and membrane receptor $G$ protein-coupled receptor 183 (GPR183, also known as EBI2 for Epstein Barr virusinduced $G$ protein-coupled receptor 2) [32, 33](Table 1). As the most broadly studied receptors, LXRs consist of two isoforms, LXR $\alpha(\mathrm{NR} 1 \mathrm{H} 3)$ and $\operatorname{LXR} \beta(\mathrm{NR} 1 \mathrm{H} 2)$. LXR $\alpha$ is expressed mainly in adipose tissue, liver, and intestine, with the highest in liver, while LXR $\beta$ is ubiquitously expressed $[34,35] .25-\mathrm{HC}$-activating LXRs are involved in a broad spectrum of physiological processes, such as cholesterol homeostasis and inflammatory response [35]. RORs are another family of nuclear receptor with three subtypes, $\mathrm{ROR} \alpha$ (NR1F1), ROR $\beta$ (NR1F2), and ROR $\gamma$ (NR1F3), with $\operatorname{ROR} \gamma$ having two isoforms, $\operatorname{ROR} \gamma 1$ and $\operatorname{ROR} \gamma t[36,37]$. 25-HC has been described as an inverse agonist of $\mathrm{ROR} \alpha$ and ROR $\gamma[38,39]$. However, there is also a study indicating that 25-HC may have some agonistic activity to $\operatorname{ROR} \gamma$ [30]. $25-\mathrm{HC}$-activating $\mathrm{ROR} \gamma \mathrm{t}$ is an essential transcription factor 


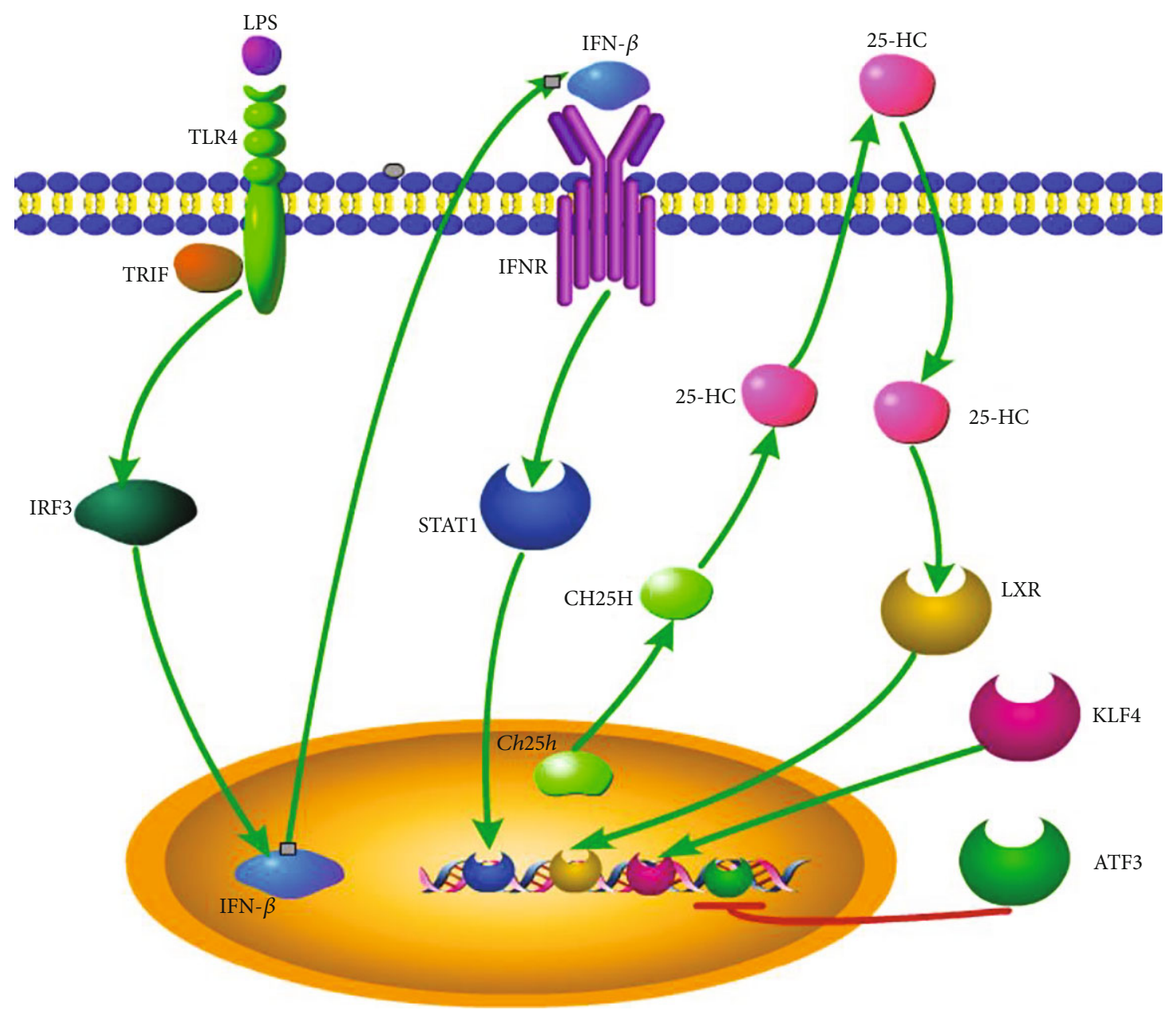

FIgURE 2: The regulation of $\mathrm{CH} 25 \mathrm{H}$ expression. In LPS-stimulated macrophages, $C h 25 h$ is induced via a TLR4/IRF3/IFN- $\beta / \mathrm{STAT} 1$ signaling pathway. In addition, anti-inflammatory transcriptional factor KLF4 transactivates Ch25h in vascular endothelial cells. On the contrary, transcriptional factor ATF3 represses Ch25h transcription via directly binding to the Ch25h promotor. Furthermore, in hepatocytes and peritoneal macrophages, $25-\mathrm{HC}$ induces $\mathrm{CH} 25 \mathrm{H}$ expression in an LXR-dependent manner. Inflammatory cytokines IL-1 $\beta$, TNF $\alpha$, and IL-6 can also promote $\mathrm{CH} 25 \mathrm{H}$ expression through the STAT1 transcription factor in virus-infected human macrophages (not shown).

of $\mathrm{T}$ helper 17 (Th17) cell differentiation [30]. In addition, 25-HC was also shown to be an agonist of ER $\alpha$-mediating gene expression changes and growth responses in breast and ovarian cancer cells [31]. Oxysterol-activating membrane receptor GPR183 directs immune cell migration [40], and 25$\mathrm{HC}$ was demonstrated to be one of its agonists [32, 33]. In fact, the most potent GPR183 endogenous agonist is 7 $\alpha, 25$-hydroxycholesterol $(7 \alpha, 25-\mathrm{HC})$, which is a $25-\mathrm{HC}$ metabolite, catalyzed by oxysterol $7 \alpha$-hydroxylase (CYP7B1) $[32,33]$.

In addition to receptors, $25-\mathrm{HC}$ is able to bind some proteins binding oxysterols, including the insulin-induced gene protein (INSIG), Niemann-Pick protein (NPC), the oxysterol-binding protein family (OSBP related, OSBPL, or ORPs), and steroidogenic acute regulatory-related lipid transfer (START) domain proteins [8] (Table 1). INSIG is a regulatory protein for the sterol regulatory element-binding protein (SREBP), which regulates the expression of enzymes involved in cholesterol biosynthesis [41]. NPC1 is a membrane glycoprotein which resides primarily in the late endosomes and transiently in lysosomes [42], and 25-HC treatment was found to recover cholesterol clearance in lyso- somal induced by NPC1 deficiency $[43,44]$. OSBP and its related proteins are a family of lipid transfer proteins (LTPs), involving in lipid metabolism and signal transduction [45]. 25-HC-activating ORP8 suppresses ATP-binding cassette transporter (ABCA1), which mediates phospholipid and cholesterol efflux and inhibits macrophage cholesterol efflux [46]. In addition, ORP8 may be implicated in 25-HCinduced apoptosis of the hepatoma cell lines, HepG2 and Huh7, via the endoplasmic reticulum (ER) stress response pathway [47]. START domain is a protein module of approximately 210 residues that binds lipids, including sterols [48]. Fifteen mammalian proteins, STARD1-STARD15, possess a START domain. 25-HC can bind to STARD4 and STARD5 $[49,50]$, indicating their role in the maintenance of cellular cholesterol homeostasis.

\section{Cholesterol and Bile Acid Metabolism}

As a primary cholesterol metabolite, 25 -HC mediates cholesterol biosynthesis, uptake, and efflux (Figure 3 ). The cholesterol homeostasis is controlled by a negative feedback loop 
TABLE 1: The receptors and binding proteins of 25-HC.

\begin{tabular}{|c|c|c|}
\hline Receptors & Role & Functions \\
\hline Liver X receptors $(\mathrm{LXR} \alpha, \mathrm{LXR} \beta)$ & $\begin{array}{l}\mathrm{LXR} \alpha \text { agonist } \\
\mathrm{LXR} \beta \text { agonist }\end{array}$ & $\begin{array}{l}\text { 1. Negatively regulates cholesterol biosynthesis and } \\
\text { promotes cholesterol efflux }[27,28,34,35] \\
\text { 2. Inflammatory regulation }[35] \\
\text { 3. Promotes pyroptosis }[83]\end{array}$ \\
\hline Retinoic-related orphan receptors $(\operatorname{ROR} \alpha, \operatorname{ROR} \beta, \operatorname{ROR} \gamma)$ & $\begin{array}{l}\text { ROR } \alpha \text { ligand } \\
\text { ROR } \gamma \text { agonist }\end{array}$ & Th17 cell differentiation $[30,36-39]$ \\
\hline Estrogen receptor $\alpha(\mathrm{ER} \alpha)$ & Agonist & $\begin{array}{l}\text { Mediates gene expression changes and growth } \\
\text { responses in breast and ovarian cancer cells [31] }\end{array}$ \\
\hline G protein-coupled receptor 183 (GPR183, EBI2) & Agonist & Directs immune cell migration $[32,33]$ \\
\hline \multicolumn{3}{|l|}{ Proteins binding oxysterols } \\
\hline Insulin-induced gene protein (INSIG) & Ligand & $\begin{array}{l}\text { Maintains SREBP in the ER and } \\
\text { inhibits cholesterol biosynthesis [41] }\end{array}$ \\
\hline Niemann-Pick protein C1 (NPC1) & Ligand & Cholesterol clearance in lysosomal [42-44] \\
\hline Oxysterol-binding protein family 8 (ORP8) & Ligand & $\begin{array}{l}\text { 1. Cholesterol efflux in macrophages [46] } \\
\text { 2. Induces apoptosis of the hepatoma cell lines [47] }\end{array}$ \\
\hline $\begin{array}{l}\text { Steroidogenic acute regulatory-related lipid } \\
\text { transfer (START) domain proteins }\end{array}$ & Ligand & Maintenance of cellular cholesterol homeostasis [48-50] \\
\hline
\end{tabular}

by cholesterol itself and its derivatives, oxysterols, with the latter ones having more potent ability to suppress cholesterol biosynthesis [51, 52]. Transcriptional factor SREBP mediates the expression of cholesterol biosynthesis ratelimiting enzyme 3-hydroxy-3-methylglutaryl-CoA reductase (HMGCR) and many other related enzymes [53, 54]. SREBPs are retained in the ER in its inactive form. To become active, SREBPs must move from the ER to the Golgi by the multitransmembrane SREBP cleavage-activating protein (SCAP) [54]. The ER membrane protein, INSIG, with the interaction of SCAP keeps the SREBP-SCAP complex remaining in the ER [41]. 25-HC can bind to INSIG, thus keeping SREBPs inactive and inhibiting cholesterol synthesis [55]. In addition, 25-HC can directly reduce the level of the rate-limiting enzyme, HMGCR, by promoting its ubiquitylation and proteasomal degradation [56].

In addition to suppressing biosynthesis, 25-HC can also promote the cholesterol to be catalyzed to bile acids and intracellular cholesterol efflux. These effects are mainly dependent on LXRs [57]. 25-HC-activating LXR $\alpha$ in hepatocytes induces the rate-limiting enzyme in the classic bile acid synthetic pathway, cholesterol $7 \alpha$-hydroxylase (CYP7A1) [57], promoting cholesterol to be converted to bile acids. In macrophages, LXRs can induce the expression of ATP-binding cassette subfamily members A1 (ABCA1) and G1 (ABCG1), which are responsible for reverse cholesterol transport, eliminating excessive intracellular cholesterol [57, 58].

Above all, it seems clear that 25-HC suppresses the cholesterol biosynthesis and promotes the intracellular cholesterol efflux through a variety of mechanisms. However, in vivo study using Ch25h knockout mice showed that $\mathrm{CH} 25 \mathrm{H}$ and $25-\mathrm{HC}$ deficiency did not affect whole cholesterol metabolism, which questioned the mediation of $25-\mathrm{HC}$ in cholesterol homeostasis $[13,14]$. These inconsistent conclusions led to the hypothesis that $25-\mathrm{HC}$ might play a role in cholesterol catabolism in a districted area and limited cells, not affecting the whole cholesterol homeostasis [12].

Bile acids are exclusively synthesized in liver through two distinct routes. In addition to the classical one initiated by CYP7A1, the so-called alternative pathway started with cholesterol 27-hydroxylase (CYP27A1) followed by oxysterols $7 \alpha$-hydroxylase (CYP7B1) $[13,59] .25-\mathrm{HC}$ is also a precursor of bile acids, although it is not so impressive as 27hydroxycholesterol (27-HC). The bile acids derived from 25 -HC count less than $5 \%$ in total per day [60]. And as like cholesterol metabolism, $\mathrm{CH} 25 \mathrm{H}$ and $25-\mathrm{HC}$ deficiency does not affect the whole bile acids homeostasis [13].

\section{Antivirus Effects}

Oxysterols link the bridge between lipid metabolism and innate and adaptive immune response [61]. As an ISG, Ch $25 h$ is highly induced in virus infection, and $25-\mathrm{HC}$ is impressive for its potent ability to inhibit virus invasion through a strand of mechanisms [62].

25-HC has a broad antivirus spectrum, including enveloped viruses and nonenveloped viruses [22, 63-72]. The enveloped viruses mainly consist of murine cytomegalovirus (MCMV), vesicular stomatitis virus (VSV), West Nile virus (WNV), the human immunodeficiency viruses (HIV), influenza virus, murid herpesvirus 68 (MHV68) and Ebola virus, Rift Valley fever virus (RVFV), Russian spring-summer encephalitis virus (RSSEV), Nipah virus, herpes simplex virus 1 (HSV-1), varicella-zoster virus (VZV), hepatitis B virus (HBV), hepatitis $\mathrm{C}$ virus (HCV), and the recently epidemic coronavirus disease 2019 (COVID-19) [22, 63-68]. The nonenveloped viruses include poliovirus, the encephalomyocarditis virus (EMCV), human papillomavirus type 16 (HPV-16), human rotavirus (HRoV), and human rhinovirus (HRhV) [69-72].

25-HC exhibits its antivirus function via a variety of mechanisms. Cholesterol metabolism is of great significance for viruses invading into the cells, the adsorption, entry, 

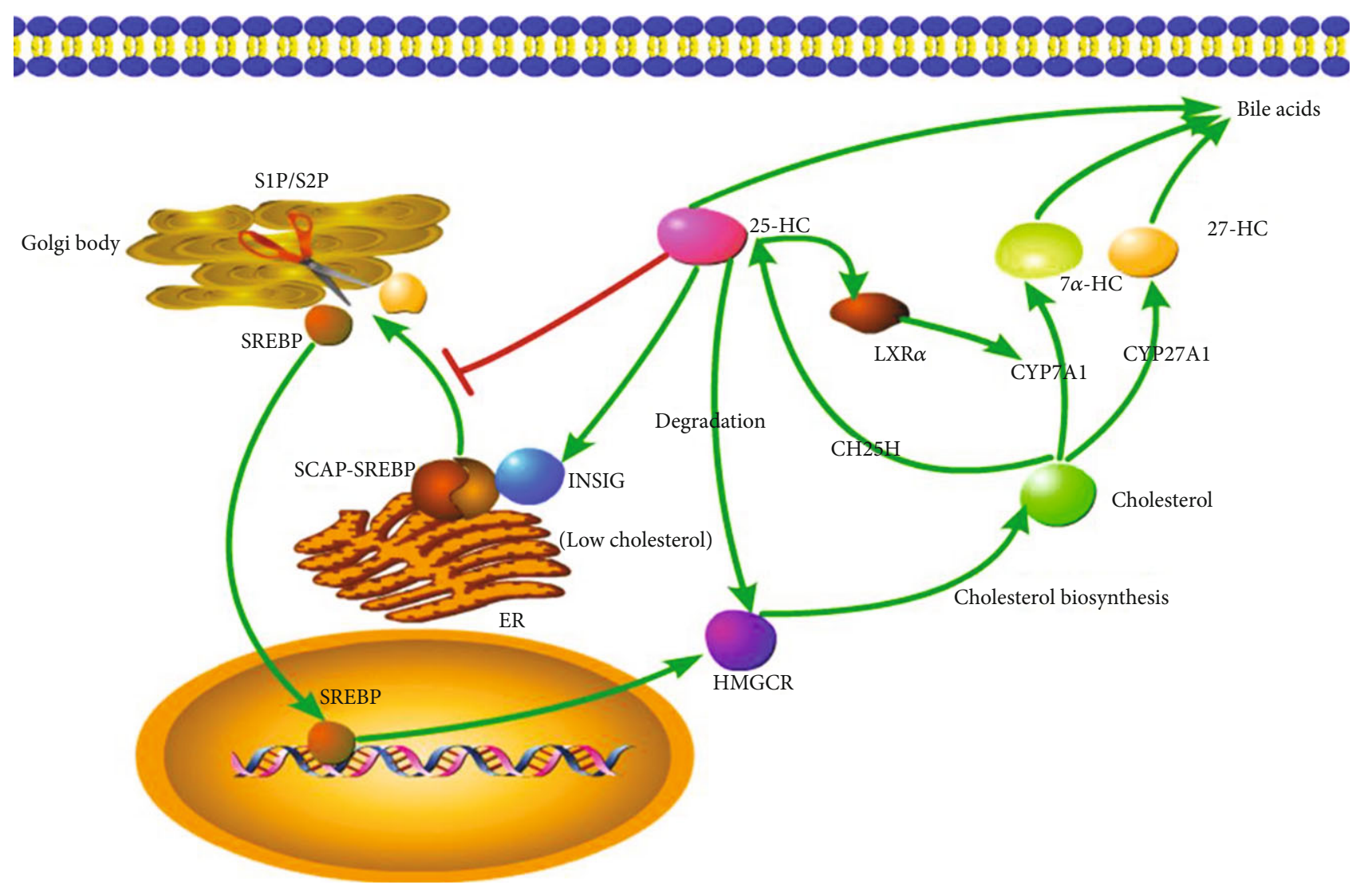

FIGURE 3: The regulation of 25-HC in cholesterol metabolism. Transcriptional factor SREBP controls the rate-limiting enzyme HMGCR. When the cholesterol level is low, the SREBP is escorted by SCAP from ER to Golgi body, in which this complex is cleaved by site-1 protease (S1P) and site-2 protease (S2P), and then the SREBP is released. 25-HC retains SREBP in ER via binds to an anchor protein INSIG in ER and suppresses SREBP translocation. Furthermore, 25-HC promotes HMGCR ubiquitylation and proteasomal degradation. 25-HC can also promote the CYP7A1 expression via activating transcriptional factor LXR $\alpha$.

assembly, budding, and release of some viruses preferentially occurring in cholesterol-enriched microdomains ("lipid rafts") of the cell membrane, especially the enveloped viruses [73]. 25-HC can directly change the position, orientation, and solvent accessibility of cholesterol in membrane, thus blocking the virus entry. Furthermore, 25-HC may insert into the cell membrane, changing the stability and integrity of cholesterol-enriched cytomembranes, inhibiting the fusion of virus and host cell membrane [74]. In addition to mediate the cell membrane status, 25-HC can also directly inhibit the virus replication. For example, the nonstructural protein 1 alpha $(\mathrm{nsp} 1 \alpha)$ is an essential protein for porcine reproductive and respiratory syndrome virus (PRRSV) replication. $\mathrm{CH} 25 \mathrm{H} / \mathrm{CH} 25 \mathrm{H}-\mathrm{M}$ could degrade nsp $1 \alpha$ through the ubiquitin-proteasome pathway [75]. Furthermore, high micromolar amounts of 25-HC-induced integrated stress response in host cells were also demonstrated to suppress the virus replication [63]. Lastly, Ch25h and 25-HC are crucial mediators in innate and adaptive immune response, and 25-HC treatment-induced inflammatory factors' release and the mediation in immune response are reported to inhibit virus invasion as well $[22,76]$.

\section{Inflammatory Response}

Does 25-HC amplify inflammatory response? It is a question. On the one hand, $25-\mathrm{HC}$ is able to suppress interleukin-1 (IL-1) family cytokine production, such as IL- $1 \alpha$, IL- $1 \beta$, and IL-18 [77, 78]. Via using Ch25h knockout mice, it was reported that $25-\mathrm{HC}$ acted by antagonizing SREBP processing to reduce IL- $1 \beta$ transcription and to broadly repress IL1 -activating inflammasomes [79]. However, the specific mechanism by which the SREBPs promote IL- $1 \beta$ transcription is not clear. The authors speculated that it might be induced by cellular lipid content alteration caused by altered SREBP activity [12]. Another study verified the effect of cellular lipid content on NLR family pyrin domain containing 3 (NLRP3) inflammasome activation. This study showed that reduced synthesis of 25-HC resulting from the lysosomal acid lipase (LIPA) inhibition, which hydrolyzes cholesteryl esters to free cholesterol for 25-HC synthesis in macrophages, contributed to defective mitochondria-associated membrane (MAM) leading to mitochondrial oxidative stress-induced NLRP3 inflammasome activation [80]. In addition, SCAP escorts both NLRP3 and SREBP2 by forming a ternary complex, and 25-HC inhibited NLRP3 
inflammasome formation via maintaining SCAP in ER [81]. Furthermore, 25-HC was found to suppress another common inflammasome activation. It was reported that high cholesterol content in macrophages was enough to activate the DNA sensor protein absent in melanoma 2 (AIM2) inflammasome by inducing impaired mitochondrial metabolism and mtDNA release, and $25-\mathrm{HC}$ was able to maintain mitochondrial integrity and prevent AIM2 inflammasome activation in activated macrophages, in which the $\mathrm{CH} 25 \mathrm{H}$ was upregulated [82] (Figure 4(a)). However, there is a study showing that 25 -HC promotes the caspase-1-dependent cell death of colon cancer cells via activating $\operatorname{LXR} \beta$, but not $\operatorname{LXR} \alpha$ [83]. And subsequent study found that 25-HC promoted robust NLRP3 inflammasome assembly and activation via potassium efflux, mitochondrial reactive oxygen species (ROS), and LXR-mediated pathways in X-linked adrenoleukodystrophy (X-ALD) [84] (Figure 4(b)). These controversial conclusions are hard to explain. It might be speculated that the function of 25-HC in NLRP3 activation may follow a tissue and cell-dependent manner.

Except for activating inflammasome, 25-HC promotes proinflammatory cytokines and chemokines, such as tumor necrosis factor- $\alpha(\mathrm{TNF} \alpha)$, interleukin-6 (IL-6), interleukin8 (IL-8), monocyte chemoattractant protein-1 (MCP1), and C-C motif chemokine ligand 2 ( $\mathrm{Ccl} 2)$ [85-90]. In addition, it is also able to suppress the secretion and production of anti-inflammatory factor interleukin-10 (IL-10). In human CD4 T cells, 25-HC reduces IL-10 production via decreasing the master transcriptional regulator of IL-10, c-Maf. In IL27 -induced type 1 regulatory T (TR1) cells, 25-HC acts as a negative regulator of TR1 cells in particular of IL-10 secretion via LXR signaling $[91,92]$.

Two transcriptional factors, nuclear factor kappa-lightchain-enhancer of activated B cells $(\mathrm{NF}-\kappa \mathrm{B})$ and Activator protein 1 (AP-1) are downstream effectors while 25-HC exerting its proinflammatory function [88, 93, 94]. And a variety of downstream signaling pathways are involved in this process. In mouse peritoneal macrophages and human umbilical cord vein endothelial cells, 25-HC induces retinoic inducible gene I (RIG-I). RIG-I transduces the signal to downstream molecules, mitochondrial antiviral-signaling protein (MAVS), transforming growth factor- $\beta$-activated kinase 1 (TAK-1), and mitogen-activated protein kinase (MAPK/ERK/P38/JNK), leading to the activation of NF- $\kappa \mathrm{B}$ and AP-1, inducing IL-8 production [95]. Furthermore, 25$\mathrm{OH}$ triggers the activation/phosphorylation of the AP-1 component c-Jun and, consistently, increases the transcriptional activity of AP-1 [96].

\section{25-HC and Cell Survival}

8.1. Autophagy. Autophagy is an evolutionarily ancient process whereby eukaryotic cells eliminate disposable or potentially dangerous cytoplasmic material to support bioenergetic metabolism and adapt to stress. It remains controversial of the function of 25-HC in mediating autophagy which is dependent on cell types. Lysosomal cholesterol accumulation sensitizes hepatocytes to acetaminophen toxicity by impairing mitophagy, and $25-\mathrm{HC}$ recovers hepatocyte mitophagy by decreasing lysosomal cholesterol accumulation [97]. However, in human glioblastoma cell line (U87-MG), $25-\mathrm{HC}$ is ineffective to restore autophagy flux and to decrease apoptosis levels [98]. In non-small-cell lung cancer cells (H1299), 25-HC is reported to induce cell death via attenuating autophagy [99].

8.2. Apoptosis. $25-\mathrm{HC}$ is reported to induce cell apoptosis in dose-dependent manner; however, the underlying mechanisms are poorly understood. Endoplasmic reticulum (ER) stress resulting from $25-\mathrm{HC}$ seems to play a key role in this oxysterol-mediated proapoptotic effect. In macrophages, oxysterol-binding protein-related protein $4 \mathrm{~L}$ (ORP4L) coexpresses and forms a complex with $\mathrm{G} \alpha \mathrm{q} / 11$ and phospholipase C- (PLC-) $\beta 3$. ORP4L facilitates PLC $\beta 3$ activation, IP3 production, and $\mathrm{Ca} 2+$ release from the endoplasmic reticulum. Through this mechanism, ORP4L sustains antiapoptotic $\mathrm{Bcl}-\mathrm{XL}$ expression through $\mathrm{Ca} 2+-$ mediated c-AMP responsive element-binding protein transcriptional regulation and thus protects macrophages from apoptosis. However, excessive $25-\mathrm{HC}$ disassembles these ORP4L/G $\alpha \mathrm{q} / 11 / \mathrm{PLC} \beta 3$ complexes, reducing PLC $\beta 3$ activity, IP3 production, and $\mathrm{Ca} 2+$ release, resulting in macrophage apoptosis [100, 101]. In hepatic cell HepG2 and Huh7, 25-HC facilitates apoptosis via enhancing endoplasmic reticulum (ER) stress, and oxysterol-binding protein-related protein 8 (ORP8) is involved in 25-HC-mediated ER stress and hepatic cell apoptosis [47]. ORP8 knockdown rescues this effect. Neutral cholesterol ester hydrolase 1 (Nceh1) is a hydrolysis enzyme that dissolves 25-HC ester to free 25-HC. Incubating Nceh1deficient thioglycollate-elicited peritoneal macrophages (TGEMs) with 25-HC caused massive accumulation of 25$\mathrm{HC}$ ester in the endoplasmic reticulum (ER) due to its defective hydrolysis, thereby activating ER stress signaling and subsequent apoptosis [102]. In addition, 25-HC is able to induce apoptosis of vascular smooth muscle cells (VSMC) by controlling mitochondrial Bax translocation and ROS formation in a soluble adenylyl cyclase (sAC)/protein kinase A(PKA-) dependent pathway [103].

\section{Conclusions and Perspective}

This review depicts the function of a kind of oxysterol, 25$\mathrm{HC}$, in cholesterol and bile acid metabolism, antivirus process, inflammatory response, and cell survival, especially in autophagy and apoptosis. It is astonishing that such a small molecule is involved in so broad variety of physiological processes. The only difference between $25-\mathrm{HC}$ and another two common primary oxysterols, $27-\mathrm{HC}$ and $24 \mathrm{~S}-\mathrm{HC}$, lies in the carbon position, to which a hydroxyl group is added. However, 25-HC has much more potent antivirus ability than the other two. The reason is not clear yet. Owing to the broad antivirus spectrum and potent antivirus effect, there is a high possibility that $25-\mathrm{HC}$ will be used as a drug in antivirus treatment. And studies exploring the specific mechanisms of 25-HC antivirus effect can be anticipated. Furthermore, the dual effects of $25-\mathrm{HC}$ in proinflammatory and anti-inflammatory lead to the hypothesis that $25-\mathrm{HC}$ may not be a simple positive or negative regulator in 


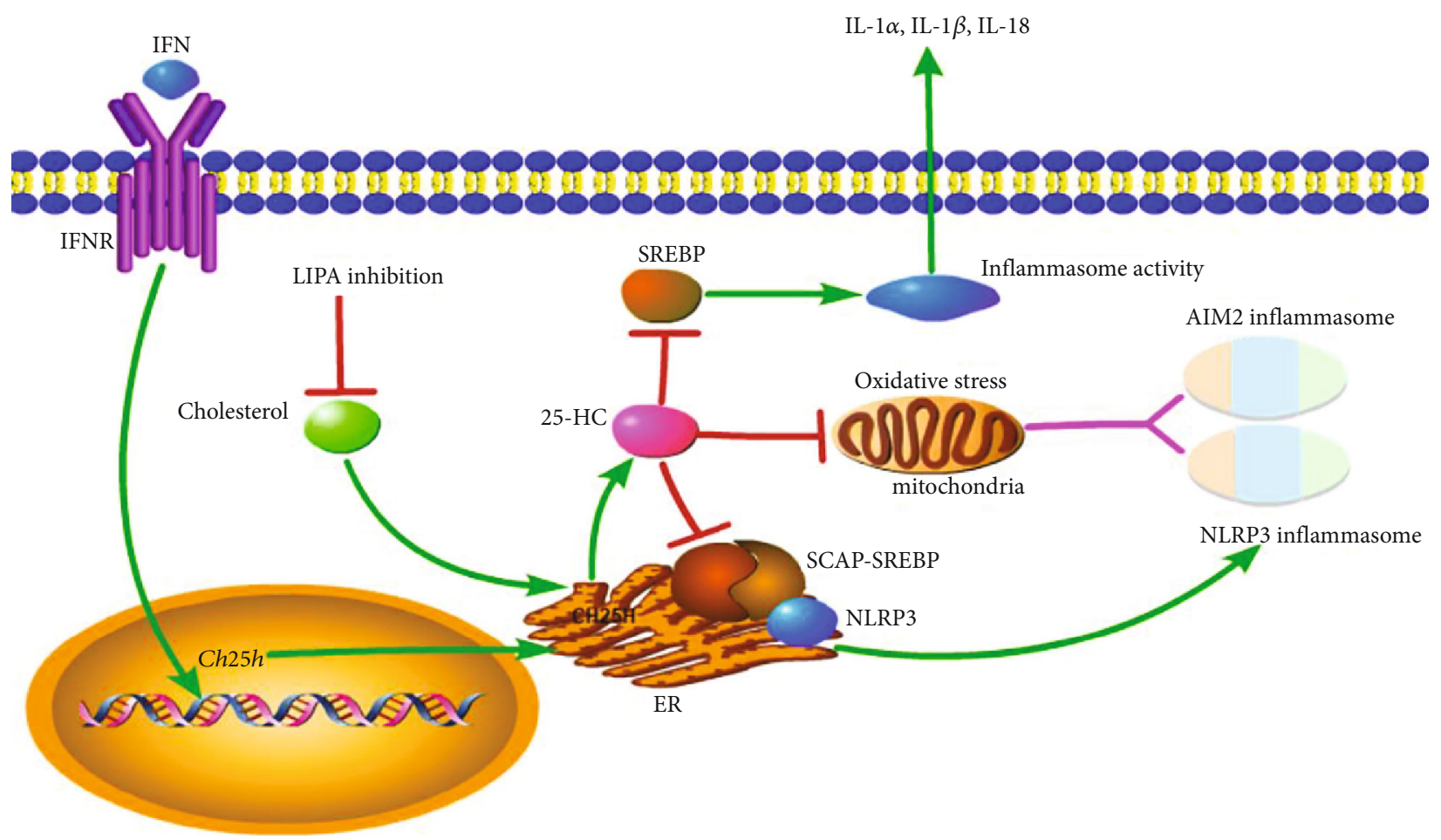

(a)

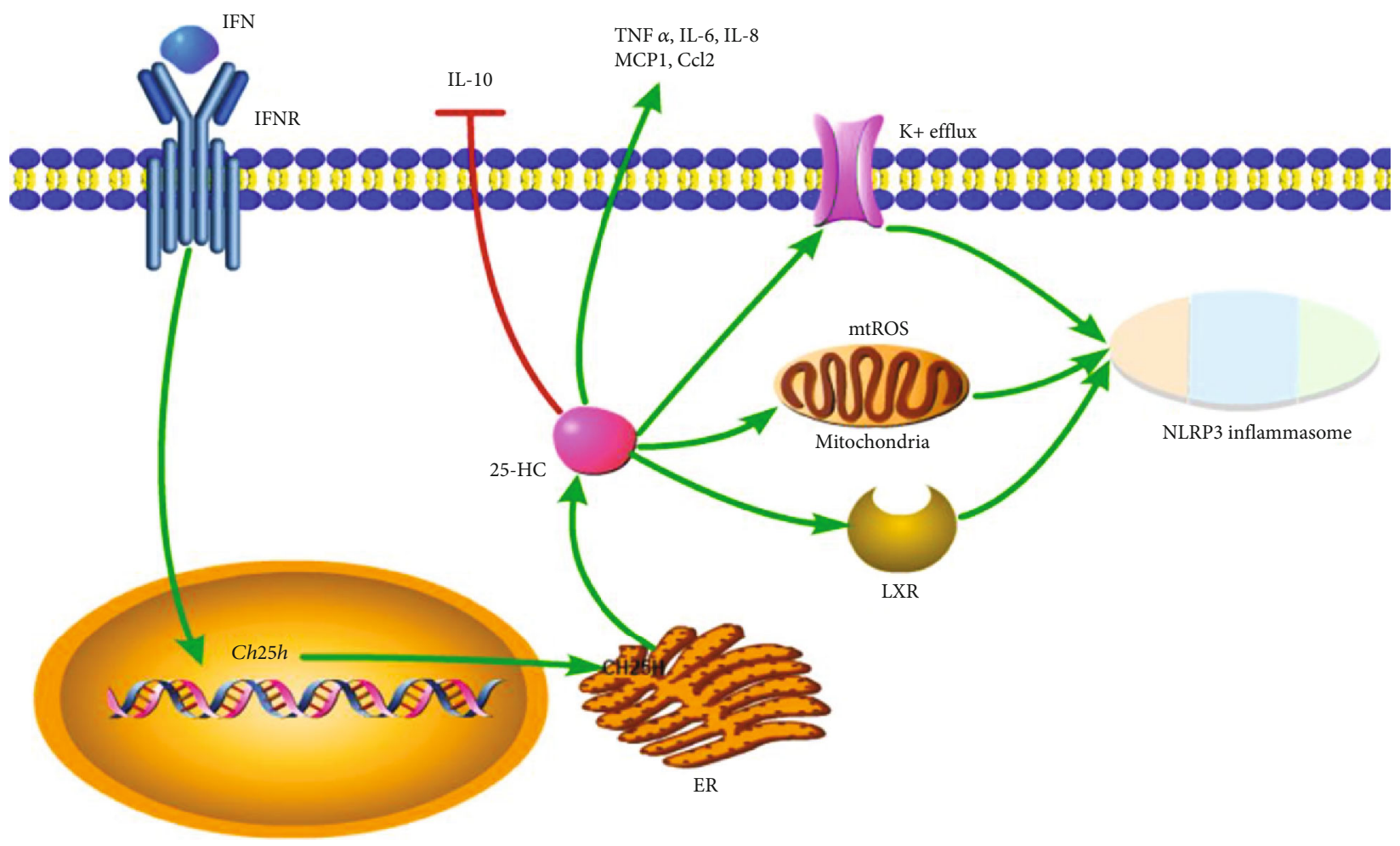

(b)

FIgure 4: (a) The anti-inflammatory effect of 25-HC. 25 -HC reduces IL-1 family (IL- $1 \alpha$, IL-1 $\beta$, and IL-18) release and inflammasome activity via inhibiting SREBP. 25-HC decreases NLRP3 and AIM2 inflammasome formation by reducing mitochondria oxidative stress. Furthermore, NLRP3 associates with SCAP and SREBP2 to form a ternary complex which translocated to the Golgi apparatus adjacent to a mitochondrial cluster for optimal inflammasome assembly, and 25-HC inhibits this process. (b) Proinflammatory effect of 25-HC. 25-HC amplifies the expression of proinflammatory factors (TNF $\alpha$, IL-6, IL-8, MCP1, and Ccl2) and reduces the anti-inflammatory factor IL-10. 25-HC promotes robust NLRP3 inflammasome assembly and activation via potassium efflux, mitochondrial ROS, and LXR-mediated pathways in brain. 
inflammatory response, but a mediator keeping inflammatory response in an accepted degree. In addition, the final phenotype in inflammatory response may be $25-\mathrm{HC}$ amount and tissue dependent. Thus, more in vivo studies are needed to tell us the whole story.

\section{Conflicts of Interest}

The authors declare that they have no conflict of interests.

\section{Acknowledgments}

This study was supported by the Medical Science Advancement Program (Clinical Medicine) of Wuhan University (no. TFLC2018003, grant to Qifa Ye) and the Joint Foundation for Translational Medicine and Interdisciplinary Research in Zhongnan Hospital (no. ZNLH201903, grant to Qifa Ye).

\section{References}

[1] L. D. Sanchez, L. Pontini, M. Marinozzi, L. C. Sanchez-Aranguren, A. Reis, and I. H. K. Dias, "Cholesterol and oxysterol sulfates: pathophysiological roles and analytical challenges," British Journal of Pharmacology, 2020.

[2] D. Sviridov, N. Mukhamedova, and Y. I. Miller, "Lipid rafts as a therapeutic target," Journal of Lipid Research, vol. 61, no. 5, pp. 687-695, 2020.

[3] P. K. Anand, "Lipids, inflammasomes, metabolism, and disease," Immunological Reviews, vol. 297, no. 1, pp. 108-122, 2020.

[4] A. Kloudova, F. P. Guengerich, and P. Soucek, "The role of oxysterols in human cancer," Trends in Endocrinology \& Metabolism, vol. 28, no. 7, pp. 485-496, 2017.

[5] D. Duc, S. Vigne, and C. Pot, "Oxysterols in autoimmunity," International Journal of Molecular Sciences, vol. 20, no. 18, article 4522, 2019.

[6] T. Willinger, "Oxysterols in intestinal immunity and inflammation," Journal of Internal Medicine, vol. 285, no. 4, pp. 367-380, 2019.

[7] G. Testa, D. Rossin, G. Poli, F. Biasi, and G. Leonarduzzi, "Implication of oxysterols in chronic inflammatory human diseases," Biochimie, vol. 153, pp. 220-231, 2018.

[8] V. Mutemberezi, O. Guillemot-Legris, and G. G. Muccioli, "Oxysterols: from cholesterol metabolites to key mediators," Progress in Lipid Research, vol. 64, pp. 152-169, 2016.

[9] A. Crosignani, M. Zuin, M. Allocca, and M. Del Puppo, "Oxysterols in bile acid metabolism," Clinica Chimica Acta, vol. 412, no. 23-24, pp. 2037-2045, 2011.

[10] B. Vurusaner, G. Leonarduzzi, P. Gamba, G. Poli, and H. Basaga, "Oxysterols and mechanisms of survival signaling," Molecular Aspects of Medicine, vol. 49, pp. 8-22, 2016.

[11] M. Moutinho, M. J. Nunes, and E. Rodrigues, "Cholesterol 24-hydroxylase: brain cholesterol metabolism and beyond," Biochimica et Biophysica Acta (BBA) - Molecular and Cell Biology of Lipids, vol. 1861, no. 12, pp. 1911-1920, 2016.

[12] J. G. Cyster, E. V. Dang, A. Reboldi, and T. Yi, "25-Hydroxycholesterols in innate and adaptive immunity," Nature Reviews Immunology, vol. 14, no. 11, pp. 731-743, 2014.
[13] D. W. Russell, "The enzymes, regulation, and genetics of bile acid synthesis," Annual Review of Biochemistry, vol. 72, no. 1, pp. 137-174, 2003.

[14] I. Björkhem, "Are side-chain oxidized oxysterols regulators also in vivo?" Journal of Lipid Research, vol. 50, Supplement, pp. S213-S218, 2009

[15] U. Diczfalusy, "On the formation and possible biological role of 25-hydroxycholesterol," Biochimie, vol. 95, no. 3, pp. 455460, 2013.

[16] E. G. Lund, T. A. Kerr, J. Sakai, W. P. Li, and D. W. Russell, "cDNA cloning of mouse and human cholesterol 25-hydroxylases, polytopic membrane proteins that synthesize a potent oxysterol regulator of lipid metabolism," The Journal of Biological Chemistry, vol. 273, no. 51, pp. 34316-34327, 1998.

[17] K. Park and A. L. Scott, "Cholesterol 25-hydroxylase production by dendritic cells and macrophages is regulated by type I interferons," Journal of Leukocyte Biology, vol. 88, no. 6, pp. 1081-1087, 2010.

[18] Y. Liu, Z. Wei, X. Ma et al., "25-Hydroxycholesterol activates the expression of cholesterol 25-hydroxylase in an LXRdependent mechanism," Journal of Lipid Research, vol. 59, no. 3, pp. 439-451, 2018.

[19] A. Honda, T. Miyazaki, T. Ikegami et al., "Cholesterol 25hydroxylation activity of CYP3A," Journal of Lipid Research, vol. 52, no. 8, pp. 1509-1516, 2011.

[20] U. Diczfalusy and I. Björkhem, "Still another activity by the highly promiscuous enzyme CYP3A4: 25-hydroxylation of cholesterol," Journal of Lipid Research, vol. 52, no. 8, pp. 1447-1449, 2011.

[21] U. Diczfalusy, K. E. Olofsson, A. M. Carlsson et al., "Marked upregulation of cholesterol 25-hydroxylase expression by lipopolysaccharide," Journal of Lipid Research, vol. 50, no. 11, pp. 2258-2264, 2009.

[22] M. Blanc, W. Y. Hsieh, K. A. Robertson et al., "The transcription factor STAT-1 couples macrophage synthesis of 25hydroxycholesterol to the interferon antiviral response," Immunity, vol. 38, no. 1, pp. 106-118, 2013.

[23] Z. Li, M. Martin, J. Zhang et al., "Krüppel-like factor 4 regulation of cholesterol-25-hydroxylase and liver $\mathrm{X}$ receptor mitigates atherosclerosis susceptibility," Circulation, vol. 136, no. 14, pp. 1315-1330, 2017.

[24] T. Magoro, A. Dandekar, L. T. Jennelle et al., "IL-1 $\beta / T N F-$ $\alpha /$ IL-6 inflammatory cytokines promote STAT1-dependent induction of $\mathrm{CH} 25 \mathrm{H}$ in Zika virus-infected human macrophages," The Journal of Biological Chemistry, vol. 294, no. 40, pp. 14591-14602, 2019.

[25] E. S. Gold, S. A. Ramsey, M. J. Sartain et al., "ATF3 protects against atherosclerosis by suppressing 25hydroxycholesterol-induced lipid body formation," The Journal of Experimental Medicine, vol. 209, no. 4, pp. 807-817, 2012.

[26] L. Ma and E. R. Nelson, "Oxysterols and nuclear receptors," Molecular and Cellular Endocrinology, vol. 484, pp. 42-51, 2019.

[27] B. A. Janowski, M. J. Grogan, S. A. Jones et al., "Structural requirements of ligands for the oxysterol liver X receptors LXRalpha and LXRbeta," Proceedings of the National Academy of Sciences of the United States of America, vol. 96, no. 1, pp. 266-271, 1999.

[28] Y. Liu, Z. Wei, Y. Zhang et al., "Activation of liver X receptor plays a central role in antiviral actions of 25- 
hydroxycholesterol," Journal of Lipid Research, vol. 59, no. 12, pp. 2287-2296, 2018.

[29] A. M. Jetten, Y. Takeda, A. Slominski, and H. S. Kang, "Retinoic acid-related orphan receptor $\gamma(\mathrm{ROR} \gamma)$ : connecting sterol metabolism to regulation of the immune system and autoimmune disease," Current Opinion in Toxicology, vol. 8, pp. 66-80, 2018.

[30] P. Soroosh, J. Wu, X. Xue et al., "Oxysterols are agonist ligands of ROR $\gamma \mathrm{t}$ and drive Th17 cell differentiation," Proceedings of the National Academy of Sciences of the United States of America, vol. 111, no. 33, pp. 12163-12168, 2014.

[31] R. Lappano, A. G. Recchia, E. M. de Francesco et al., "The cholesterol metabolite 25-hydroxycholesterol activates estrogen receptor $\alpha$-mediated signaling in cancer cells and in cardiomyocytes," PLoS One, vol. 6, no. 1, article e16631, 2011.

[32] S. Hannedouche, J. Zhang, T. Yi et al., "Oxysterols direct immune cell migration via EBI2," Nature, vol. 475, no. 7357, pp. 524-527, 2011.

[33] C. Liu, X. V. Yang, J. Wu et al., "Oxysterols direct B-cell migration through EBI2," Nature, vol. 475, no. 7357, pp. 519-523, 2011.

[34] K. Endo-Umeda and M. Makishima, "Liver X receptors regulate cholesterol metabolism and immunity in hepatic nonparenchymal cells," International Journal of Molecular Sciences, vol. 20, no. 20, article 5045, 2019.

[35] S. Leussink, I. Aranda-Pardos, and N. A-Gonzalez, "Lipid metabolism as a mechanism of immunomodulation in macrophages: the role of liver X receptors," Current Opinion in Pharmacology, vol. 53, pp. 18-26, 2020.

[36] I. Dzhagalov, N. Zhang, and Y. W. He, "The roles of orphan nuclear receptors in the development and function of the immune system," Cellular \& Molecular Immunology, vol. 1, no. 6, pp. 401-407, 2004.

[37] L. Zhao, S. Zhou, and J. Å. Gustafsson, "Nuclear receptors: recent drug discovery for cancer therapies," Endocrine Reviews, vol. 40, no. 5, pp. 1207-1249, 2019.

[38] N. Kumar, L. A. Solt, J. J. Conkright et al., “The benzenesulfoamide T0901317 [N-(2,2,2-trifluoroethyl)-N-[4-[2,2,2-trifluoro-1-hydroxy-1-(trifluoromethyl)ethyl]phenyl]-benzenesulfonamide] is a novel retinoic acid receptor-related orphan receptor-alpha/gamma inverse agonist," Molecular Pharmacology, vol. 77, no. 2, pp. 228-236, 2010.

[39] L. Jin, D. Martynowski, S. Zheng, T. Wada, W. Xie, and Y. Li, "Structural basis for hydroxycholesterols as natural ligands of orphan nuclear receptor RORgamma," Molecular Endocrinology, vol. 24, no. 5, pp. 923-929, 2010.

[40] V. Daugvilaite, K. N. Arfelt, T. Benned-Jensen, A. W. Sailer, and M. M. Rosenkilde, "Oxysterol-EBI2 signaling in immune regulation and viral infection," European Journal of Immunology, vol. 44, no. 7, pp. 1904-1912, 2014.

[41] S. Ouyang, Z. Mo, S. Sun, K. Yin, and Y. Lv, "Emerging role of Insig-1 in lipid metabolism and lipid disorders," Clinica Chimica Acta, vol. 508, pp. 206-212, 2020.

[42] S. Wheeler and D. J. Sillence, "Niemann-Pick type C disease: cellular pathology and pharmacotherapy," Journal of Neurochemistry, vol. 153, no. 6, pp. 674-692, 2020.

[43] X. Feng, C. Cozma, S. Pantoom et al., "Determination of the pathological features of NPC1 variants in a cellular complementation test," International Journal of Molecular Sciences, vol. 20, no. 20, article 5185, 2019.
[44] A. Frolov, S. E. Zielinski, J. R. Crowley, N. Dudley-Rucker, J. E. Schaffer, and D. S. Ory, "NPC1 and NPC2 regulate cellular cholesterol homeostasis through generation of low density lipoprotein cholesterol-derived oxysterols," The Journal of Biological Chemistry, vol. 278, no. 28, pp. 25517-25525, 2003.

[45] A. Pietrangelo and N. D. Ridgway, "Bridging the molecular and biological functions of the oxysterol-binding protein family," Cellular and Molecular Life Sciences, vol. 75, no. 17, pp. 3079-3098, 2018.

[46] D. Yan, M. I. Mäyränpää, J. Wong et al., “OSBP-related protein 8 (ORP8) suppresses ABCA1 expression and cholesterol efflux from macrophages," The Journal of Biological Chemistry, vol. 283, no. 1, pp. 332-340, 2008.

[47] J. Li, X. Zheng, N. Lou, W. Zhong, and D. Yan, "Oxysterol binding protein-related protein 8 mediates the cytotoxicity of 25-hydroxycholesterol," Journal of Lipid Research, vol. 57, no. 10, pp. 1845-1853, 2016.

[48] F. Alpy and C. Tomasetto, "Give lipids a START: the StARrelated lipid transfer (START) domain in mammals," Journal of Cell Science, vol. 118, no. 13, pp. 2791-2801, 2005.

[49] D. Rodriguez-Agudo, S. Ren, P. B. Hylemon et al., "Human StarD5, a cytosolic StAR-related lipid binding protein," Journal of Lipid Research, vol. 46, no. 8, pp. 1615-1623, 2005.

[50] D. Rodriguez-Agudo, S. Ren, P. B. Hylemon et al., "Localization of StarD5 cholesterol binding protein," Journal of Lipid Research, vol. 47, no. 6, pp. 1168-1175, 2006.

[51] M. S. Brown and J. L. Goldstein, "Cholesterol feedback: from Schoenheimer's bottle to Scap's MELADL," Journal of Lipid Research, vol. 50, Supplement, pp. S15-S27, 2009.

[52] W. J. Griffiths and Y. Wang, "Oxysterol research: a brief review," Biochemical Society Transactions, vol. 47, no. 2, pp. 517-526, 2019.

[53] D. B.-B. RA and J. Ye, "SREBPs in lipid metabolism, insulin signaling, and beyond," Trends in Biochemical Sciences, vol. 43 , no. 5, pp. 358-368, 2018.

[54] X. Cheng, J. Li, and D. Guo, "SCAP/SREBPs are central players in lipid metabolism and novel metabolic targets in cancer therapy," Current Topics in Medicinal Chemistry, vol. 18, no. 6, pp. 484-493, 2018.

[55] A. Radhakrishnan, Y. Ikeda, H. J. Kwon, M. S. Brown, and J. L. Goldstein, "Sterol-regulated transport of SREBPs from endoplasmic reticulum to Golgi: oxysterols block transport by binding to Insig," Proceedings of the National Academy of Sciences of the United States of America, vol. 104, no. 16, pp. 6511-6518, 2007.

[56] Y. Gong, J. N. Lee, P. C. W. Lee, J. L. Goldstein, M. S. Brown, and J. Ye, "Sterol-regulated ubiquitination and degradation of Insig-1 creates a convergent mechanism for feedback control of cholesterol synthesis and uptake," Cell Metabolism, vol. 3, no. 1, pp. 15-24, 2006.

[57] B. Wang and P. Tontonoz, "Liver X receptors in lipid signalling and membrane homeostasis," Nature Reviews. Endocrinology, vol. 14, no. 8, pp. 452-463, 2018.

[58] C. P. Sparrow, J. Baffic, M. H. Lam et al., “A potent synthetic LXR agonist is more effective than cholesterol loading at inducing ABCA1 mRNA and stimulating cholesterol efflux," The Journal of Biological Chemistry, vol. 277, no. 12, pp. 10021-10027, 2002.

[59] A. Worthmann, C. John, M. C. Rühlemann et al., "Coldinduced conversion of cholesterol to bile acids in mice shapes 
the gut microbiome and promotes adaptive thermogenesis," Nature Medicine, vol. 23, no. 7, pp. 839-849, 2017.

[60] N. B. Javitt, "Cholesterol, hydroxycholesterols, and bile acids," Biochemical and Biophysical Research Communications, vol. 292, no. 5, pp. 1147-1153, 2002.

[61] M. J. Hubler and A. J. Kennedy, "Role of lipids in the metabolism and activation of immune cells," The Journal of Nutritional Biochemistry, vol. 34, pp. 1-7, 2016.

[62] J. Zhao, J. Chen, M. Li, M. Chen, and C. Sun, "Multifaceted functions of $\mathrm{CH} 25 \mathrm{H}$ and $25 \mathrm{HC}$ to modulate the lipid metabolism, immune responses, and broadly antiviral activities," Viruses, vol. 12, no. 7, p. 727, 2020.

[63] N. Shibata, A. F. Carlin, N. J. Spann et al., "25-Hydroxycholesterol activates the integrated stress response to reprogram transcription and translation in macrophages," The Journal of Biological Chemistry, vol. 288, no. 50, pp. 35812-35823, 2013.

[64] S. Y. Liu, R. Aliyari, K. Chikere et al., "Interferon-inducible cholesterol-25-hydroxylase broadly inhibits viral entry by production of 25-hydroxycholesterol," Immunity, vol. 38, no. 1, pp. 92-105, 2013.

[65] V. Cagno, A. Civra, D. Rossin et al., "Inhibition of herpes simplex-1 virus replication by 25-hydroxycholesterol and 27-hydroxycholesterol," Redox Biology, vol. 12, pp. 522-527, 2017.

[66] M. Iwamoto, K. Watashi, S. Tsukuda et al., "Evaluation and identification of hepatitis B virus entry inhibitors using HepG2 cells overexpressing a membrane transporter NTCP," Biochemical and Biophysical Research Communications, vol. 443, no. 3, pp. 808-813, 2014.

[67] S. M. Sagan, Y. Rouleau, C. Leggiadro et al., "The influence of cholesterol and lipid metabolism on host cell structure and hepatitis C virus replication," Biochemistry and Cell Biology, vol. 84, no. 1, pp. 67-79, 2006.

[68] S. Yuan, C. C. Y. Chan, K. K. H. Chik et al., "Broad-spectrum host-based antivirals targeting the interferon and lipogenesis pathways as potential treatment options for the pandemic coronavirus disease 2019 (COVID-19)," Viruses, vol. 12, no. 6 , p. $628,2020$.

[69] M. Arita, H. Kojima, T. Nagano, T. Okabe, T. Wakita, and H. Shimizu, "Oxysterol-binding protein family I is the target of minor enviroxime-like compounds," Journal of Virology, vol. 87, no. 8, pp. 4252-4260, 2013.

[70] S. Li, L. Li, H. Zhu et al., "Cholesterol 25-hydroxylase inhibits encephalomyocarditis virus replication through enzyme activity-dependent and independent mechanisms," Veterinary Microbiology, vol. 245, article 108658, 2020.

[71] A. Civra, V. Cagno, M. Donalisio et al., "Inhibition of pathogenic non-enveloped viruses by 25 -hydroxycholesterol and 27-hydroxycholesterol," Scientific Reports, vol. 4, no. 1, article 7487, 2015.

[72] A. Civra, R. Francese, P. Gamba et al., "25-Hydroxycholesterol and 27-hydroxycholesterol inhibit human rotavirus infection by sequestering viral particles into late endosomes," Redox Biology, vol. 19, pp. 318-330, 2018.

[73] J. P. Pombo and S. Sanyal, "Perturbation of intracellular cholesterol and fatty acid homeostasis during flavivirus infections," Frontiers in Immunology, vol. 9, article 1276, 2018.

[74] A. A. Bielska, B. N. Olsen, S. E. Gale et al., "Side-chain oxysterols modulate cholesterol accessibility through membrane remodeling," Biochemistry, vol. 53, no. 18, pp. 3042-3051, 2014.

[75] W. Ke, L. Fang, H. Jing et al., "Cholesterol 25-hydroxylase inhibits porcine reproductive and respiratory syndrome virus replication through enzyme activity-dependent and -independent mechanisms," Journal of Virology, vol. 91, no. 19, article e00827, 2017.

[76] T. Wu, F. Ma, X. Ma et al., "Regulating innate and adaptive immunity for controlling SIV infection by 25 -hydroxycholesterol," Frontiers in Immunology, vol. 9, article 2686, 2018.

[77] K. Ludigs, V. Parfenov, R. A. Du Pasquier, and G. Guarda, "Type I IFN-mediated regulation of IL-1 production in inflammatory disorders," Cellular and Molecular Life Sciences, vol. 69, no. 20, pp. 3395-3418, 2012.

[78] G. Guarda, M. Braun, F. Staehli et al., "Type I interferon inhibits interleukin-1 production and inflammasome activation," Immunity, vol. 34, no. 2, pp. 213-223, 2011.

[79] A. Reboldi, E. V. Dang, J. G. McDonald, G. Liang, D. W. Russell, and J. G. Cyster, "Inflammation. 25-Hydroxycholesterol suppresses interleukin-1-driven inflammation downstream of type I interferon," Science, vol. 345, no. 6197, pp. 679684, 2014.

[80] M. Viaud, S. Ivanov, N. Vujic et al., "Lysosomal cholesterol hydrolysis couples efferocytosis to anti-inflammatory oxysterol production," Circulation Research, vol. 122, no. 10, pp. 1369-1384, 2018.

[81] C. Guo, Z. Chi, D. Jiang et al., "Cholesterol homeostatic regulator SCAP-SREBP2 integrates NLRP3 inflammasome activation and cholesterol biosynthetic signaling in macrophages," Immunity, vol. 49, no. 5, pp. 842-856.e7, 2018.

[82] E. V. Dang, J. G. McDonald, D. W. Russell, and J. G. Cyster, "Oxysterol restraint of cholesterol synthesis prevents AIM2 inflammasome activation," Cell, vol. 171, no. 5, pp. 10571071.e11, 2017.

[83] V. Derangère, A. Chevriaux, F. Courtaut et al., "Liver X receptor $\beta$ activation induces pyroptosis of human and murine colon cancer cells," Cell Death and Differentiation, vol. 21, no. 12, pp. 1914-1924, 2014.

[84] J. Jang, S. Park, H. Jin Hur et al., "25-hydroxycholesterol contributes to cerebral inflammation of X-linked adrenoleukodystrophy through activation of the NLRP3 inflammasome," Nature Communications, vol. 7, no. 1, article 13129, 2016.

[85] M. Y. Wong, M. Lewis, J. J. Doherty et al., "25-Hydroxycholesterol amplifies microglial IL- $1 \beta$ production in an apoE isoform-dependent manner," Journal of Neuroinflammation, vol. 17, no. 1, p. 192, 2020.

[86] S. M. Pokharel, N. K. Shil, J. B. GC et al., "Integrin activation by the lipid molecule 25 -hydroxycholesterol induces a proinflammatory response," Nature Communications, vol. 10, no. 1, article 1482, 2019.

[87] H. Fu, F. Spieler, J. Großmann et al., "Interleukin-1 potently contributes to 25-hydroxycholesterol-induced synergistic cytokine production in smooth muscle cell-monocyte interactions," Atherosclerosis, vol. 237, no. 2, pp. 443-452, 2014.

[88] P. Palozza, R. Simone, A. Catalano et al., "Lycopene prevention of oxysterol-induced proinflammatory cytokine cascade in human macrophages: inhibition of NF- $\kappa \mathrm{B}$ nuclear binding and increase in PPAR $\gamma$ expression," The Journal of Nutritional Biochemistry, vol. 22, no. 3, pp. 259-268, 2011. 
[89] B. Dugas, S. Charbonnier, M. Baarine et al., "Effects of oxysterols on cell viability, inflammatory cytokines, VEGF, and reactive oxygen species production on human retinal cells: cytoprotective effects and prevention of VEGF secretion by resveratrol," European Journal of Nutrition, vol. 49, no. 7, pp. 435-446, 2010.

[90] C. Prunet, T. Montange, A. Véjux et al., "Multiplexed flow cytometric analyses of pro- and anti-inflammatory cytokines in the culture media of oxysterol-treated human monocytic cells and in the sera of atherosclerotic patients," Cytometry Part A, vol. 69A, no. 5, pp. 359-373, 2006.

[91] E. Perucha, R. Melchiotti, J. A. Bibby et al., "The cholesterol biosynthesis pathway regulates IL-10 expression in human Th1 cells," Nature Communications, vol. 10, no. 1, p. 498, 2019.

[92] S. Vigne, F. Chalmin, D. Duc et al., "IL-27-induced type 1 regulatory T-cells produce oxysterols that constrain IL-10 production," Frontiers in Immunology, vol. 8, article 1184, 2017.

[93] L. Xu, S. Shen, Y. Ma et al., "25-Hydroxycholesterol-3-sulfate attenuates inflammatory response via PPAR $\gamma$ signaling in human THP-1 macrophages," American Journal of Physiology. Endocrinology and Metabolism, vol. 302, no. 7, pp. E788-E799, 2012.

[94] I. L. M. H. Aye, B. J. Waddell, P. J. Mark, and J. A. Keelan, "Oxysterols exert proinflammatory effects in placental trophoblasts via TLR4-dependent, cholesterol-sensitive activation of NF- $\kappa$ B," Molecular Human Reproduction, vol. 18, no. 7, pp. 341-353, 2012.

[95] F. Wang, W. Xia, F. Liu, J. Li, G. Wang, and J. Gu, "Interferon regulator factor $1 /$ retinoic inducible gene I (IRF1/RIG-I) axis mediates 25 -hydroxycholesterol-induced interleukin-8 production in atherosclerosis," Cardiovascular Research, vol. 93, no. 1, pp. 190-199, 2012.

[96] S. Lemaire-Ewing, A. Berthier, M. C. Royer et al., "7 $\beta$-Hydroxycholesterol and 25-hydroxycholesterol-induced interleukin- 8 secretion involves a calcium-dependent activation of $\mathrm{c}$-fos via the ERK1/2 signaling pathway in THP-1 cells," Cell Biology and Toxicology, vol. 25, no. 2, pp. 127139, 2009.

[97] A. Baulies, V. Ribas, S. Núñez et al., "Lysosomal cholesterol accumulation sensitizes to acetaminophen hepatotoxicity by impairing mitophagy," Scientific Reports, vol. 5, no. 1, article 18017, 2016.

[98] P. M. Tricarico, R. Gratton, L. Braga, F. Celsi, and S. Crovella, " 25 -Hydroxycholesterol and inflammation in Lovastatinderegulated mevalonate pathway," The International Journal of Biochemistry \& Cell Biology, vol. 92, pp. 26-33, 2017.

[99] H. Kim, S. Y. Choi, J. Lim, A. M. Lindroth, and Y. J. Park, "EHMT2 inhibition induces cell death in human non-small cell lung cancer by altering the cholesterol biosynthesis pathway," International Journal of Molecular Sciences, vol. 21, no. 3, article 1002, 2020.

[100] M. Charman, T. R. Colbourne, A. Pietrangelo, L. Kreplak, and N. D. Ridgway, "Oxysterol-binding protein (OSBP)related protein 4 (ORP4) is essential for cell proliferation and survival," The Journal of Biological Chemistry, vol. 289, no. 22, pp. 15705-15717, 2014.

[101] W. Zhong, G. Pan, L. Wang et al., "ORP4L facilitates macrophage survival via G-protein-coupled signaling: ORP4L-/mice display a reduction of atherosclerosis," Circulation Research, vol. 119, no. 12, pp. 1296-1312, 2016.
[102] M. Sekiya, D. Yamamuro, T. Ohshiro et al., "Absence of Nceh1 augments 25-hydroxycholesterol-induced ER stress and apoptosis in macrophages," Journal of Lipid Research, vol. 55, no. 10, pp. 2082-2092, 2014.

[103] Q. Dong, Y. Chen, W. Liu et al., "25-Hydroxycholesterol promotes vascular calcification via activation of endoplasmic reticulum stress," European Journal of Pharmacology, vol. 880, article 173165, 2020. 